WRPS-50343

Revision 0

\title{
A Revised Method for Estimating Oxide Basicity Per the Smith Scale, with Example Application to Glass Durability
}

Prepared for the U.S. Department of Energy

Assistant Secretary for Environmental Management

Contractor for the U.S. Department of Energy

Office of River Protection under Contract DE-AC27-08RV14800

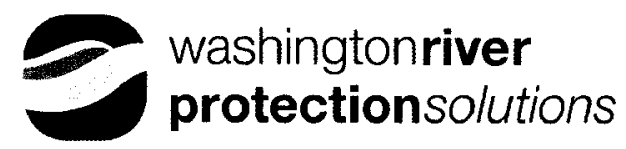

P.O. Box 850

Richland, Washington 99352 
WRPS-50343

Revision 0

\section{A Revised Method for Estimating Oxide Basicity Per the Smith Scale, with Example Application to Glass Durability}

Jacob G. Reynolds

Washington River Protection Solutions

Date Published

July 2011

To Be Presented at

Journal of Solid State Sciences

Published in

Journal

Prepared for the U.S. Department of Energy

Assistant Secretary for Environmental Management

Contractor for the U.S. Department of Energy

Office of River Protection under Contract DE-AC27-08RV14800

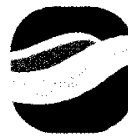

washingtonriver protectionsolutions

P.O. Box 850

Richland, Washington

Copyright License

By acceptance of this article, the publisher and/or recipient acknowledges the U.S. Government's right to retain a nonexclusive, royalty-free license in and to any copyright covering this paper.

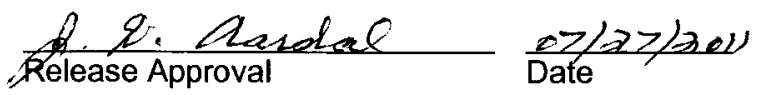


WRPS-50343

Revision 0

LEGAL DISCLAIMER

This report was prepared as an account of work sponsored by an agency of the United States Government. Neither the United States Government nor any agency thereof, nor any of their employees, nor any of their contractors, subcontractors or their employees, makes any warranty, express or implied, or assumes any legal liability or responsibility for the accuracy,

completeness, or any third party's use or the results of such use of any information, apparatus, product, or process disclosed, or represents that its use would not infringe privately owned rights. Reference herein to any specific commercial product, process, or service by trade name, trademark, manufacturer, or otherwise, does not necessarily constitute or imply its endorsement, recommendation, or favoring by the United

States Government or any agency thereof or its contractors or subcontractors. The views and opinions of authors expressed herein do not necessarily state or reflect those of the United States Government or any agency thereof.

This report has been reproduced from the best available copy. Available in paper copy. 
A Revised Method for Estimating Oxide Basicity Per the Smith Scale, with Example Application to Glass Durability

Jacob G. Reynolds

Washington River Protection Solutions, LLC

PO Box 850

Richland, WA, 99352 


\begin{abstract}
Previous researchers have developed correlations between oxide electronegativity and oxide basicity. The present paper revises those correlations using a newer method of calculating electronegativity of the oxygen anion. Basicity is expressed using the Smith $\alpha$ parameter scale. A linear relation was found between the oxide electronegativity and the Smith $\alpha$ parameter, with an $R^{2}$ of 0.92 . An example application of this new correlation to the durability of high-level nuclear waste glass is demonstrated. The durability of waste glass was found to be directly proportional to the quantity and basicity of the oxides of tetrahedrally-coordinated network forming ions.
\end{abstract}

\title{
1. Introduction
}

The concept of oxide basicity is widely used in oxide chemistry. There are several scales used to classify oxide basicity [1-3]. Portier et al. [4] has determined that two of the scales, the optical basicity scale [1] and the Smith [2] $\alpha$ parameter scale, are equivalent and can be used to estimate each other. The Smith [2] scale is particularly interesting because it can be determined directly from thermodynamic data, which is more widely available than the optical spectroscopy methods used to measure optical basicity. Nonetheless, the optical basicity scale has become more popular than the Smith scale. Given the correlations in Portier et al. [4], the optical basicity can be calculated from the Smith basicity without the need to resort to optical spectroscopic measurements. Portier et al. [4] has suggested there is a linear relationship between the Smith $\alpha$ parameter and electronegativity, where the Smith $\alpha$ parameter is the measure of basicity in the Smith scale. This same research group has since derived a better way to calculate electronegativity of the oxygen anion in oxides [5]. Consequently, the present paper will update 
the relationship between Smith scale and electronegativity using the oxygen anion electronegativity of Campet et al. [5].

The Smith scale can be and is best determined from thermodynamic data [2], which is widely available for common oxides. Consequently, the relation developed in this paper would be most useful for oxides that cannot be synthesized in a pure form, such as oxyanions, because enthalpies of formation cannot be determined on these types of oxides directly from calorimetry. Another application would be to multicomponent oxides when the reactivity of only one of the oxide components is of interest. An example application of the new correlation to the durability of glass produced from the vitrification of multicomponent nuclear waste will be given. This study will show that the impact of network-forming oxides on the overall glass on durability is highly correlated to the basicity of those oxides, as expected from theory $[6,7]$.

\section{Modeling Approach}

Smith [2] assumed that the acidity of an oxide could be defined by its tendency to accept an oxygen anion from a basic oxide. Smith [2] defined a parameter, the Smith Alpha $\left(\alpha_{i}\right)$, for each oxide (i) that scales the tendency of the oxide to accept an oxygen anion. The Smith $\alpha$ is related to the enthalpy of the reaction between the acidic and basic cations by the relation:

$\left[\alpha_{A}(A)-\alpha_{B}(B)\right]^{2}=h(A, B) \quad$ Equation 1 
where $\mathrm{A}$ and $\mathrm{B}$ are the stoichiometry of the acidic and basic cations, $\alpha_{\mathrm{A}}$ and $\alpha_{\mathrm{B}}$ are the Smith $\alpha$ parameter for the acidic and basic oxide, and $\mathrm{h}(\mathrm{A}, \mathrm{B})$ is the change in enthalpy during the reaction. The Smith scale is anchored by defining the Smith $\alpha$ of water as zero.

Bratsch [8] has proposed that enthalpies of formation of oxides could be determined from the Smith $\alpha$ parameter if the parameter could be estimated from some non-thermodynamic source. Bratsch [8] proposed that the Smith $\alpha$ parameter could be estimated from the electronegativity of the oxides. Portier et al. [4] proposed their own functional relationship between the Smith $\alpha$ parameter and the electronegativity scale developed by the lead author [9]. In the Portier et al. [9] scale, the electronegativity of cations in oxides $\left(\chi_{M}\right)$ is estimated from the bond lengths and charge through the equation:

$\chi_{M}=0.274 * z-0.15 * z * r-0.01 r+1+b$

Equation 2

where $\mathrm{z}$ is the charge on the cation and $\mathrm{r}$ is the radius, which depends on the coordination environment [10]. The variable " $b$ " was called " $\alpha$ " by the original authors but was renamed $b$ here to avoid confusion with the Smith $\alpha$. The quantity $\mathrm{b}$ in Equation 2 is an element specific constant reported in Portier et al. [9]. The total electronegativity of the oxide was determined by Portier et al. [4] using the following equation:

$$
\chi_{\text {oxide }}=\left[\left(\chi_{M}\right)^{m} *\left(\chi_{O}\right)^{n}\right]^{1 /(m+n)} \quad \text { Equation } 3
$$

where $\chi_{M}$ and $\chi_{O}$ are the electronegativities of the cation and oxygen anion, respectively, and $m$ is the stoichometery of the cation in the oxide while $\mathrm{n}$ is the stoichiometry of the oxygen anion in the oxide. 
Portier et al. [4] used Equation 2 to estimate the electronegativities of the cations $\left(\chi_{M}\right)$, but they used the Pauling electronegativity for the oxygen anion electronegativity $\left(\chi_{0}\right)$. Since 2003 , that same research group has developed an improved estimate of the electronegativity of the oxygen anion, which depends on the cation to which the oxygen is bound [5]. The purpose of this paper is to determine the relationship between the electronegativities of oxides and the Smith $\alpha$ parameter using the revised oxygen anion electronegativity equation developed by Campet et al. [5] so that an improved estimate of Smith $\alpha$ can be obtained. The revised equation for electronegativity of the oxygen anion is [5]:

$$
\chi_{O}=-0.35\left(\chi_{M}\right)^{2}+1.77\left(\chi_{M}\right)+1.1 \quad \text { Equation } 4
$$

According to Campet et al. [5], Equation 4 is not valid for oxygen anions bound to metal ions with partially filled $\mathrm{d}$ orbitals. Consequently, transition metal ions with partially filled d orbitals were excluded from the present correlation unless they had no crystal field stabilization energy, such as $\mathrm{Mn}$ (II) and Fe(III). Table 1 contains all of the oxides used in the present study, along with the electronegativities calculated from Equations 2 through 4, and the Smith $\alpha$ parameters reported by Smith [2]. As shown in Figure 1, there is a linear relationship between the oxide electronegativity and the Smith $\alpha$ parameter. Regression of this data leads to the following formula with an $\mathrm{R}^{2}$ statistic of 0.92 :

$\alpha=11.33 \chi-26.989$

Equation 5 
Figure 1. Correlation between Basicity (Smith $\alpha$ Parameter) and Oxide Electronegativity

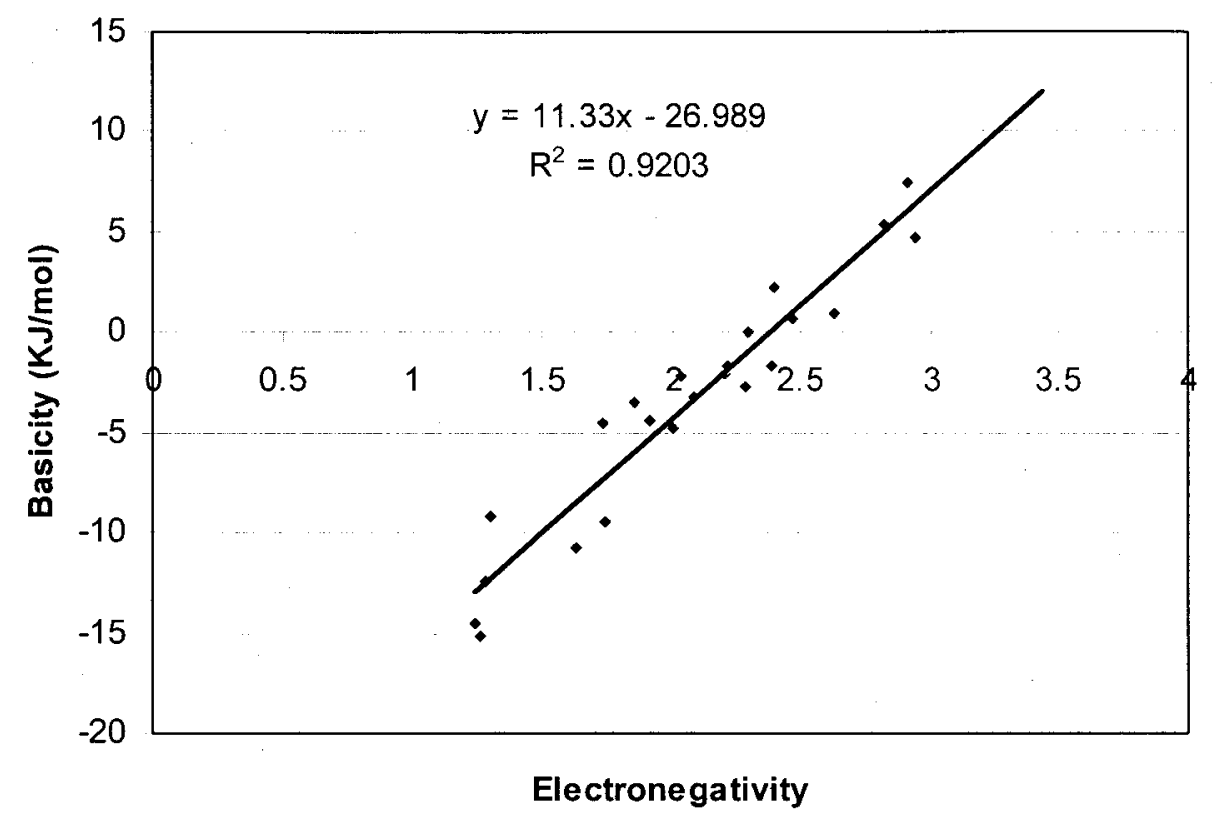

Smith [2] reported that the average standard deviation of Smith $\alpha$ parameters determined from heats of reaction were between 0.2 to $1 \mathrm{KJ} / \mathrm{mol}$, with most clustering around $0.5 \mathrm{KJ} / \mathrm{mol}$. The differences between Smith's [2] values and those predicted from Equation 5 range from 0.05 for $\mathrm{Al}_{2} \mathrm{O}_{3}$ to 3.06 for $\mathrm{Li}_{2} \mathrm{O}$. This indicates that the Smith $\alpha$ parameters measured by calorimetry are more precise than the values predicted from the regression equation, and the values derived from thermodynamic data should be used when available. The high $\mathrm{R}^{2}$ yet large residuals (measured minus predicted) indicate that the electronegativity as calculated by Equations 2 through 5 explains most but not all of the oxide basicity. The precision shown in Figure 1 is sufficient to distinguish acidic from basic oxides but cannot distinguish between 
small differences in oxide basicity [11]. As is evident by the high $\mathrm{R}^{2}$ statistic (0.92), Equation 5 is accurate over the entire range of electronegativities. Most residuals (measured minus predicted values) were much less than $3 \mathrm{KJ} / \mathrm{mol}$. Table 1 compares the measured and predicted values for each of the oxides considered by the regression.

Table 1. Electronegativities and Smith $\alpha$ for Oxides used in Regression.

\begin{tabular}{|c|c|c|c|}
\hline Oxide & Electronegativity (Eq 3) & Smith $\alpha$ from Calorimetry [2] & Predicted Smith $\alpha$ (eq. 5) \\
\hline $\mathrm{Al}_{2} \mathrm{O}_{3}$ & 2.210 & -2 & -1.95 \\
\hline $\mathrm{As}_{2} \mathrm{O}_{5}$ & 2.826 & 5.4 & 5.03 \\
\hline $\mathrm{BaO}$ & 1.630 & -10.8 & -8.57 \\
\hline $\mathrm{BeO}$ & 2.033 & -2.2 & -3.96 \\
\hline $\mathrm{CeO}_{2}$ & 2.289 & -2.7 & -1.05 \\
\hline $\mathrm{CdO}$ & 1.911 & -4.4 & -5.33 \\
\hline $\mathrm{Cs}_{2} \mathrm{O}$ & 1.255 & -15.2 & -12.77 \\
\hline $\mathrm{Fe}_{2} \mathrm{O}_{3}$ & 2.384 & -1.7 & 0.020 \\
\hline $\mathrm{Ga}_{2} \mathrm{O}_{3}$ & 2.219 & -1.6 & -1.85 \\
\hline $\mathrm{HgO}$ & 1.858 & -3.5 & -5.94 \\
\hline $\mathrm{K}_{2} \mathrm{O}$ & 1.235 & -14.6 & -12.99 \\
\hline $\mathrm{Li}_{2} \mathrm{O}$ & 1.299 & -9.2 & -12.26 \\
\hline $\mathrm{MnO}^{\mathrm{N} O}$ & -4.8 & -4.22 \\
\hline $\mathrm{Na}_{2} \mathrm{O}$ & 2.009 & -12.5 & -12.43 \\
\hline $\mathrm{P}_{4} \mathrm{O}_{10}$ & 1.284 & 7.5 & 6.02 \\
\hline $\mathrm{PbO}^{2}$ & 2.913 & -4.5 & -7.40 \\
\hline $\mathrm{SiO}_{2}$ & 1.729 & 0.9 & 2.83 \\
\hline $\mathrm{SnO}_{2}$ & 2.632 & 2.2 & 0.20 \\
\hline $\mathrm{SrO}_{\mathrm{TiO}}$ & 2.400 & -9.4 & -7.23 \\
\hline $\mathrm{WO}_{3}$ & 1.744 & 0.7 & 0.974 \\
\hline $\mathrm{ZnO}_{\mathrm{ZnO}}$ & 2.468 & 4.7 & 6.30 \\
\hline & 2.938 & -3.2 & -3.3 \\
\hline & 2.089 & 0.1 & -0.92 \\
\hline
\end{tabular}

\section{Application}

The preferred way to determine the Smith $\alpha$ for an oxide is from enthalpy of formation data for the oxide and reaction products, as done by Smith [2]. However, there are situations when this type of data is not 
realistically available. An example would be when one is interested in only the reactive sites of a multicomponent oxide, because the local basicity of a multi-component oxide is not the same as the overall basicity of the oxide. For instance, Duffy et al. [12] found that the basicity at the iron atoms in ironbearing silicate glasses is not the same as the average basicity of the glass. The local susceptibility to acid-base reactions of a multi-component oxide may depend on the basicity of that portion of the oxide. An example of this will be shown for nuclear waste glass durability in order to demonstrate the applicability of Equation 5.

Much of the nuclear waste generated around the world will be vitrified and the resulting waste glass will be buried in a geological repository. The durability of waste glass is a contributing factor to the release of long-lived radionuclides into the environment. The dissolution of these glasses is governed by ionexchange reactions between alkali in the glass and acids in solution as well as the hydrolysis of bridging oxygen bonds [13]. The hydrolysis of these bridging oxygen bonds is believed to be from nucleophilic attack by basic hydroxide ions from the aqueous phase $[6,7]$. Given that this hydrolysis reaction is an acid-base reaction, the susceptibility of these bonds to hydrolysis likely depends on the basicity of the network forming ions. Feng and Barkatt [14] hypothesized that the relative impact of oxides on glass durability is a function of the hydration enthalpy of the oxides. Given that the hydrolysis of bonds is believed to be an acid-base reaction, and that Smith $\alpha$ defines the basicity of an oxide in terms of its enthalpy of formation relative to water (which is proportional to the hydration enthalpy), it follows that the relative effect of different network-forming oxides on durability will be proportional to the Smith $\alpha$ of the oxides. This hypothesis is tested here.

The early-stage dissolution of glass in water is believed to be driven by the ion exchange reactions between hydronium ions in the liquid phase and glass network modifiers in the glass phase [13, 15]. This ion-exchange reaction is followed by an attack on the bridging oxygen bonds of the network formers from hydroxide ions in solution $[6,7,13]$. Given that most sodium species are highly soluble, sodium can be 
used to follow the extent of the ion-exchange reaction. Many of the network formers, however, have limited solubility and they re-precipitate or re-polymerize on the glass surface $[16,17]$. This reprecipitation or re-polymerization creates a gel-phase on the surface that may be able to slow the reaction down in the long run [16]. Boron is a network former that is soluble and not incorporated into the gel appreciably (18). Therefore, the concentration of boron in the liquid phase is used as an indicator of the destruction of the glass network. In the present study, the susceptibility of the network to attack by hydroxide is the acid-base reaction of interest.

The gel-layer on the glass surface may act as a barrier to long term destruction of the glass $[16,17,19]$. Therefore, the short-term dissolution of the glass is the best-indicator of the relative susceptibility of the glass to attack by hydroxide. The long term performance of the glass is also dependent on the concentration of ions in the liquid [20,21], which may come from other sources than glass dissolution. Therefore, the product consistency Test (PCT) has been developed to evaluate the relative durability of glass [22], without being subject to these other complicating factors. In the PCT, glass powders of a defined particle size are immersed in hot water for 7 days, and the release of indicator ions from the glass into solution is measured. Boron release is used as an indicator of the dissolution of the glass network [18]. The PCT response changes with glass composition; therefore, the PCT test is an indicator of the relative performance of glasses in this short period [22]. Isotopic exchange experiments have confirmed that glass hydrolysis is the primary control of glass durability during the time frame of the PCT test, rather than the formation of a protective layer [23]. Consequently, PCT response can be regarded as the relative rate of glass dissolution up to 7 days of time.

The PCT response changes with glass composition, and glass composition changes with waste composition and formulation approach. Consequently, waste vitrification facilities have developed models to predict PCT response as a function of glass composition so that acceptable glass can be 
formulated [24]. A popular PCT model is the first order mixture model where the natural logarithm of the normalized boron release is described as a first order function of the glass composition [25]:

$\ln$ normolized boron release $=\sum r_{i} m_{i}$

Equation 6

where $m_{i}$ is the mole fraction of constituent " $i$ " and $r_{i}$ is an empirically determined coefficient that describes the relative impact of the constituent on durability. The accuracy of the model and the values of the coefficients depend somewhat on the size of and components in the glass composition region of interest [26]. Vienna et al. [25] report a set of model coefficients applicable to a broad range of glass compositions relevant to the vitrificaiton of radioactive waste in the United States. The $r_{i}$ coefficients the report for the oxides of the most prevalent network forming ions in nuclear waste glass (silica, boron, aluminum, and ferric iron) are shown in Table 2. In nuclear waste glass, these ions are predominantly, though not entirely, coordinated by four oxygens $[27,28]$. The measured basicity value for $\mathrm{SiO}_{2}$ is available (Table 1) but measured Smith $\alpha$ parameters for $\mathrm{Fe}_{2} \mathrm{O}_{3}, \mathrm{Al}_{2} \mathrm{O}_{3}$, and $\mathrm{B}_{2} \mathrm{O}_{3}$ are not available for the case where the cations are coordinated by four oxygens. The $\mathrm{Fe}_{2} \mathrm{O}_{3}$ and $\mathrm{Al}_{2} \mathrm{O}_{3}$ in Table 1 represent the case where $\mathrm{Fe}$ and $\mathrm{Al}$ are coordinated by six oxygens. Consequently the Smith $\alpha$ parameter for $\mathrm{Fe}_{2} \mathrm{O}_{3}$, $\mathrm{Al}_{2} \mathrm{O}_{3}$, and $\mathrm{B}_{2} \mathrm{O}_{3}$ for four-coordinate $\mathrm{Fe}, \mathrm{Al}$, and $\mathrm{B}$ was calculated using Equations 2 through 5 and the results are shown in Table 2 . The difference between the oxide electronegativity of four and six coordinated cations is in the ionic radius used in Equation 2 [10].

Table 2. First Order Mixture Model Coefficients [25] and Smith $\alpha$ Parameters for Dominant Network Oxides of Tetrahedrally Coordinated Cations in Nuclear Waste Glass.

\begin{tabular}{|l|c|c|}
\hline \multicolumn{1}{|c|}{ Tetrahedral Oxide } & $\mathbf{r}_{1}$ (Equation 6) & Smith $\alpha$ \\
\hline $\mathrm{SiO}_{2}$ & -4.352 & 0.9 \\
\hline
\end{tabular}




\begin{tabular}{|l|c|c|}
\hline $\mathrm{Fe}_{2} \mathrm{O}_{3}$ & -9.692 & 0.73 \\
\hline $\mathrm{Al}_{2} \mathrm{O}_{3}$ & -28.483 & -1.22 \\
\hline $\mathrm{B}_{2} \mathrm{O}_{3}$ & 13.749 & 2.06 \\
\hline
\end{tabular}

Figure 2 presents the $r_{i}$ coefficients for Equation 6, a measure of the oxide's impact on glass durability, against the basicity, as defined by the Smith $\alpha$. As can be seen in Figure 2, there is roughly a linear relationship between durability and basicity for these four tetrahedrally coordinated network formers. This result is consistent with theory [6] and the observations of Reynolds [7].

Figure 2. Correlation between Basicity and the First Order Mixture Model Coefficients for the Oxides of the Tetrahedrally-Coordinated Network Forming Ions.

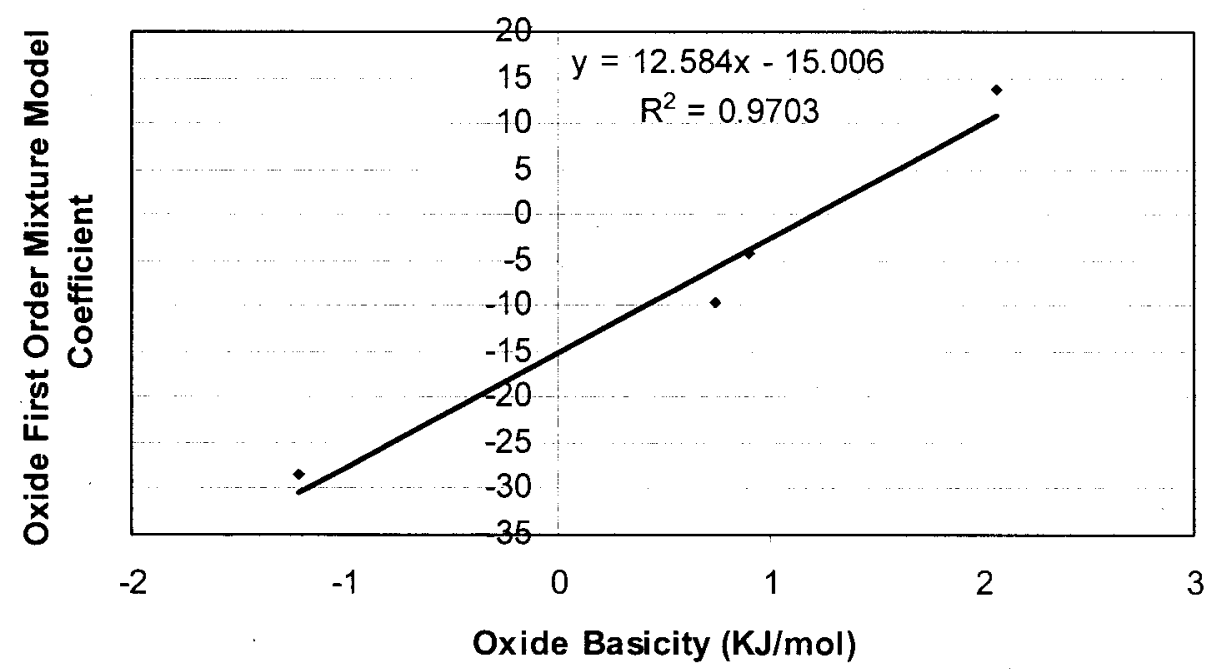

\section{Conclusion}


A new relationship between oxide basicity, as measured by the Smith $\alpha$ parameter [2], and the electronegativity of the oxide was developed (Equation 5). A linear relation was found between the Smith $\alpha$ and the oxide electronegativity as calculated by the methods of references [4] and [5]. This relationship can be used to distinguish basic oxides from acidic oxides. An example application of this equation to nuclear waste glass durability was used. The relative impact of tetrahedrally coordinated network formers on glass durability was found to be proportional to the basicity of those oxides, as expected from theory.

\section{References}

[1] J.A. Duffy, M. D. Ingram, J. Am. Chem. Soc. 93 (1971) 6448.

[2] D. W. Smith, J. Chem. Educ. 64 (1988) 480.

[3] M. M. Pivovarov, Glass Phys. Chem. 27 (2001) 22.

[4] J. Portier, P. Poizot, J. M. Tarascon, G. Campet, M. A. Subramanian, Solid State Science 5 (2003) 695.

[5] G. Campet, J. Portier, M. A. Subramanian, Materials Lett. 58 (2004) 437.

[6] A. C. Lasaga, Rev. Mineralogy, 31 (1995) 23.

[7] J. G. Reynolds, Ceramic Transactions 176 (2005) 201. 
[8] S. G. Bratsch, J. Chem. Educ. 65 (1988) 877.

[9] J. Portier, P. G. Campet, B. Tanguy, J. Alloys Compounds 209 (1994) 285.

[10] R. D. Shannon, Acta Cryst. A32 (1976) 751.

[11] D. S. Moore, G. P. McCabe, Introduction to the Practice of Statistics, 2nd ed. W.H. Freeman and Company, New York, 1993

[12] J.A., Duffy, M. D. Ingram, S. Fong, Phys. Chem. Chem. Phys. 2 (2000) 1829.

[13] B. C. Bunker, Mat. Res. Soc. Symp. Proc. 84, (1987) 493.

[14] X. Feng, A. Barkatt, Mat. Res. Soc. Symp. Proc. 112 (1988) 543.

[15] B. P. McGrail, J. P. Icenhower, D. K. Shuh, P. Liu, J. G. Darab, D. R. Baer, S. Thevuthasen, V.

Shutthanandan, M. H. Engelhard, C. H. Booth, and P. Machimuthu, J. Non-Crystalline Solids, 296, 10-26 (2001).

[16] B.C. Sales, C.W. White, G.M. Begun, and L.A. Boatner. J. Non-Crystalline Solids, 67 (1984), 245.

[17] L.A. Zellmer, and W.B. White. 1985. Mat. Res. Soc. Symp. Proc. 44, (1985) 73.

[18] B. E. Sheets, W. P. Freeborn, D. K. Smith, C. Anderson, M. Zolensky, Mat. Res. Soc. Symp. Proc. 44, (1985) 129. 
[19] P.K. Abraitis, B.P. McGrail, and D.P. Trivedi, Mat. Res. Soc, Symp. Proc. 556, (1999), 401.

[20] J.C. Sang, and A. Barkett. Phys. Chem. Glasses, 36 (1995), 95.

[21] C.L. Wickert, A.E. Vieira, J.A. Dehne, X. Wang, D.M. Wilder, and A. Barkett. Phys. Chem. Glasses, 40 (1999), 157.

[22] ASTM, Standard Test Methods for Determining Chemical Durability of Nuclear, Hazardous, and Mixed Waste Glasses and Multiphase Glass Ceramics: The Product Consistency Test (PCT), ASTM C 1285-02, 2002, West Conshoken, PA. (2002)

[23] X. Feng, , L. Fu, T. K. Choudhury, I. L. Pegg, and P. B. Macedo, Mat. Res. Soc. Symp. Proc., 212, (1991) 49-56

[24] A. Ellison, Ceramic Transactions 61, (1995) 417.

[25] J. D. Vienna, D. S. Kim, P. Hrma, Ceramic Transactions 146 (2002) 151.

[26] G. F. Piepel, T. E. Redgate, P. Masuga, Glass Tech. 38 (1997) 210.

[27] E. De Grave, A.D. Stalios, A. Van Alboom, J. Nuclear Mat. 171 (1990) 189.

[28] J. C. Darab, J. C. Linehan, B. P. McGrail, Mat. Res. Soc. Symp. Ser., 556 (1999) 337. 